\title{
Patient Age, Race and the Type of Diabetes Have an Impact on the Presenting Symptoms, Latency Before Diagnosis and Laboratory Abnormalities at Time of Diagnosis of Diabetes Mellitus in Children
}

\author{
Anıl R. Kumar, Paul B. Kaplowitz \\ Department of Pediatrics, Virginia Commonwealth University, Medical College of Virginia, Richmond, VA, USA \\ *Department of Endocrinology, Children's National Medical Center, Washington, DC, USA
}

\begin{abstract}
Objective: To correlate the presence and duration of the symptoms with laboratory data in children with new onset diabetes mellitus (DM) and to determine the impact of gender, race, age, and type of diabetes on these relationships.

Methods: This was a single institution prospective study in which we asked the families of 112 children with new-onset DM a standard set of questions concerning the presence and duration of symptoms. We then reviewed selected laboratory data and explored the relationships between the symptoms, laboratory findings, gender, age, race, type of diabetes (T1DM or T2DM), and presence or absence of a history of diabetes in a close relative. Results: Over 90\% of patients had polyuria and polydipsia (mean duration 17 and 19 days), but only $50 \%$ of the families sought medical attention for this complaint. Children less than 5 years of age and African American children with T1DM were more dehydrated at presentation. More profound acidosis was seen in patients of younger age ( $<5$ years), those with greater weight loss ( $9 \%$ or higher), and those with higher initial serum glucose $(p<0.01)$. Mean hemoglobin A1c ( $\mathrm{HbA1c})$ was close to $11 \%$ for each subgroup and strongly correlated with the proportion of weight loss $(\mathrm{p}=0.0015)$, but not with the initial blood glucose, corrected serum sodium, or BUN levels.

Conclusions: Parents of children with new onset DM might not report polyuria or polydypsia as their main concern when they seek medical attention, so primary care physicians must be alert to the diagnosis of diabetes in any child with significant weight loss. Young children $(<5$ years old) and African American children with new onset T1DM are more dehydrated and young children ( $<5$ years old) are more acidotic.

Key words: Type 1 diabetes, type 2 diabetes, new onset, hemoglobin A1c
\end{abstract}

Received: 20.04 .2009

Accepted: 03.08.2009

\section{Introduction}

Diabetes mellitus (DM) is one of the most common endocrine conditions and the incidence and prevalence of both type 1 DM (T1DM) and type 2 DM (T2DM) are increasing among children $(1,2)$. The initial complaint and presenting symptoms vary considerably from only mild symptoms to diabetic ketoacidosis (DKA) and shock. Some children are described by their parents to be symptomatic for only a few days prior to diagnosis, while others have had symptoms for several weeks. It is not clear to what extent a prolonged symptomatic period predicts the severity of dehydration or laboratory abnormalities at diagnosis. Furthermore, only a few previous studies have reported laboratory data and presenting symptoms in new-onset childhood diabetes. These were over a decade ago and did not examine the impact of race on the presentation of T1DM, nor did they include T2DM as a separate group. It is possible that increased provider and public awareness of diabetes as well as the increased incidence of T2DM among children might have had an impact on the initial presentation of diabetes in children. To address these issues, we collected data on initial symptoms, symptom duration, and initial laboratory data on all newly diagnosed patients with diabetes at our institution over a period of 18 consecutive months and explored relationships between these variables, and the possible impact of age, race and gender, presence: of diabetes in a close relative, and the type of diabetes (T1DM or T2DM) on the type and duration of symptoms as well as extent of laboratory' : ibrormalities.

\footnotetext{
Address for Correspondence

AnIl R. Kumar, PO Box 980140, West hospital, 15 Fi Floor, Richmond VA, USA 23298-0140

Phone: +00 804-747-5087 Fax: +00 804-828-3256 E-mail: arkumar@mail2.vcu.edu

(c) Journal of Clinical Research in Pediatric Endocrinology, Published by Galenos Publishing. All rights reserved.
} 


\section{Methods}

This study was approved by the Institutional Review Board of the Virginia Commonwealth University Health System. Between March 2002 and July 2003, 112 families of children with new onset DM seen at the Virginia Commonwealth University Health System were asked a standard set of questions (in most cases within 24 hours of diagnosis). The demographics of the study sample match the population served by the hospital and the entire community it serves. All the 112 children who were eligible during this time period were enrolled in the study. They were asked if any of the symptom(s) that brought them to medical attention included polyuria, polydipsia, nocturia, polyphagia, abdominal pain, unusual fatigue, vomiting, and genital discharge or rash, all of which are known to be associated with DM. They were then asked the duration of each symptom. The presence of weight loss was estimated as the difference between admission weight and parental recall of the child's weight at a recent (1-4 months preceding) health care visit. Family history for T1DM and T2DM (adult onset was assumed to be T2DM) was recorded. For analysis, we accepted only those with a history of T1DM or T2DM in a first or second degree relative (siblings, parents, grandparents, aunts, and uncles) as being a positive family history in a close relative.

A review of the initial laboratory tests included blood glucose, electrolytes, BUN, hemoglobin $\mathrm{A} 1 \mathrm{c}(\mathrm{HbA} 1 \mathrm{c})$, and urine ketones. Most of the $\mathrm{HbA} 1 \mathrm{c}$ tests were done at the MCV Hospital using the HPLC assay (Primus) that has a normal range of $4.3-5.5 \%$. The corrected sodium ( $\mathrm{Na}$ ) was calculated for each patient using the formula $\mathrm{Na}+$ (blood glucose-100/1.6)). Elevated corrected $\mathrm{Na}$, like elevated BUN, reflected a greater degree of dehydration. We did not record $\mathrm{pH}$ values since they were not available for many patients who presented without DKA, but used the serum bicarbonate ( $\mathrm{HCO}_{3}$ ) level as an index of the severity of acidosis.

We defined a subset of patients (all of whom were African American) as having T2DM if they were obese and had acanthosis nigricans. Since most but not all patients with T2DM have acanthosis nigricans (3), it is possible that a few of the African American children classified as T1DM may have actually had T2DM. Clinical signs helpful in distinguishing T2DM from T1DM are obesity and signs of insulin resistance (acanthosis nigricans, hypertension, polycystic ovary syndrome). Patients with T2DM frequently have elevated C-peptide levels. The absence of auto-antibodies to insulin, to islet cells, or to glutamic acid decarboxylase is also typical in most (but not all) cases of diabetes that are classified as T2DM (11). We did not measure antibody, C-peptide or insulin level in our patients. All these patients continue to show signs of insulin resistance on follow up for 2-3 years.

\section{Statistical Methods}

Mean values were calculated for the duration of each symptom and laboratory parameter. The entire group was then stratified according to race (African American or Caucasian), type of diabetes (T1DM or T2DM), age group ( $\leq 5$ years, $6-12$ years and $\geq 13$ years), and family history of diabetes (present or absent). The mean values were compared by ANOVA. Linear regression analysis was applied to individual variables using Pearson correlation coefficients. The $\mathrm{p}$ values were defined as statistically significant when $<0.05$. Nonsignificant values were denoted as NS.

\section{Results}

Of the 112 children in the study, 20.5\% were younger than 5 years of age, $47.3 \%$ were between 6 and 12 years, and $32.1 \%$ were older than 13 years of age. Both genders were similarly represented (47\% males and $53 \%$ females). T1DM was diagnosed in 56\% of Caucasian children and 24\% of African American children. T2DM was diagnosed in 20\% of children, all of whom were African American.

Polydipsia, polyuria and nocturia were the most common symptoms and were reported in $89-93 \%$ of patients while polyphagia was noted in only $19 \%$. The mean duration of these symptoms was 16.8 days for polyuria, 17.3 days for

Table 1. Frequency of the presenting symptoms

\begin{tabular}{|c|c|c|c|c|c|}
\hline Symptom & $\begin{array}{l}\text { All Patients } \\
\text { Number (No.)/ } \\
\text { Percent (\%) }\end{array}$ & $\begin{array}{l}\text { All patients } \\
\text { Mean duration in } \\
\text { days } \pm S D\end{array}$ & $\begin{array}{c}\text { Caucasian } \\
\text { T1DM } \\
\text { No. } / \%\end{array}$ & $\begin{array}{c}\text { African American } \\
\text { T1DM } \\
\text { No. } / \%\end{array}$ & $\begin{array}{c}\text { African American } \\
\text { T2DM } \\
\text { No. } / \%\end{array}$ \\
\hline Polydipsia & $101 / 91$ & $19.3 \pm 21.4$ & $55 / 83$ & $25 / 100$ & $21 / 100$ \\
\hline Polyuria & $103 / 93$ & $16.8 \pm 17.7$ & $57 / 86$ & $25 / 100$ & $21 / 100$ \\
\hline Nocturia & $98 / 89$ & $17.3 \pm 20.8$ & $59 / 89$ & $24 / 96$ & $15 / 71$ \\
\hline Polyphagia & $21 / 19$ & $17.3 \pm 23.9$ & $13 / 19$ & $6 / 24$ & $2 / 9$ \\
\hline Weight loss* & $75 / 67$ & ------- & $57 / 86$ & $18 / 72$ & $0 / 0$ \\
\hline Fatigue & $70 / 63$ & $9.7 \pm 10.7$ & $38 / 57$ & $17 / 68$ & $15 / 71$ \\
\hline Abdominal pain & $42 / 38$ & $9.2 \pm 13.5$ & $27 / 41$ & $9 / 36$ & $6 / 28$ \\
\hline Vomiting once & $19 / 17$ & $1.4 \pm 1.6$ & $11 / 17$ & $2 / 8$ & $6 / 28$ \\
\hline Vomiting more than once & $31 / 28$ & $1.6 \pm 0.9$ & $15 / 23$ & $10 / 40$ & $6 / 28$ \\
\hline Genital rash / discharge & $11 / 10$ & $11.1 \pm 17.1$ & $4 / 6$ & $4 / 16$ & $3 / 14$ \\
\hline
\end{tabular}


nocturia and 19.3 days for polydypsia (Table 1). Fatigue (63\%) and weight loss (68\%) were the next most common symptoms, while abdominal pain (38\%) and vomiting (45\%) were reported less frequently. Among the patients with vomiting, there was a single episode of emesis in 19 (38\%), often more than a day before they sought medical attention. In 31 patients (62\%), there were multiple episodes of emesis. Genital rash or discharge was noted in $10 \%$ of all patients, and in $19 \%$ of females.
Only $50 \%$ the parents reported taking their child to a physician because of polyuria and polydypsia and surprisingly, only $8 \%$ took their child for medical attention due to weight loss (Table 2). Nineteen percent reported their major concern was their child's color and/or appearance.

Table 3 shows duration of polydipsia, estimated \% weight loss, and laboratory values when the entire group was stratified by race, type of diabetes, age group, and the

Table 2. Symptoms reported as prompting parents to seek medical attention*

\begin{tabular}{|c|c|c|c|c|}
\hline $\begin{array}{l}\text { Symptoms } \\
\text { Prompting Visit }\end{array}$ & $\begin{array}{c}\text { All Patients } \\
\%\end{array}$ & $\begin{array}{l}\text { Caucasian } \\
\text { T1DM \% }\end{array}$ & $\begin{array}{c}\text { African American } \\
\text { T1DM \% }\end{array}$ & $\begin{array}{c}\text { African American } \\
\text { T2DM \% }\end{array}$ \\
\hline Polyuria and Polydypsia & 50 & 53 & 48 & 43 \\
\hline Appearance/ color not good & 19 & 18 & 28 & 9 \\
\hline Vomiting & 15 & 12 & 20 & 18 \\
\hline Fatigue & 13 & 15 & 8 & 14 \\
\hline Weight loss\# & 8 & 9 & 8 & 4 \\
\hline Abdominal pain & 5 & 4 & 8 & 4 \\
\hline Routine physical exam & 5 & 0 & 20 & 0 \\
\hline Genital rash/discharge & 3 & 1 & 4 & 4 \\
\hline
\end{tabular}

Table 3. Duration of polydipsia, $\%$ weight loss, and selected laboratory tests for different patient subgroups (mean \pm SD)

\begin{tabular}{|c|c|c|c|c|c|c|c|c|}
\hline Group & $\mathbf{N}$ & $\begin{array}{l}\text { Duration of } \\
\text { polydipsia } \\
\text { (days) }\end{array}$ & $\begin{array}{l}\% \text { weight } \\
\text { loss (n) }\end{array}$ & $\begin{array}{l}\text { Glucose } \\
\mathrm{mmol} / \mathrm{L} \\
\text { (mg/dl) }\end{array}$ & $\begin{array}{c}\text { Corrected } \\
\text { sodium } \\
\text { mmol/L }\end{array}$ & $\begin{array}{c}\mathrm{HCO}_{3} \\
\mathrm{mmol} / \mathrm{L}\end{array}$ & $\begin{array}{l}\text { BUN } \\
\mathrm{mmol} / \mathrm{L} \\
(\mathrm{mg} / \mathrm{dl})\end{array}$ & $\begin{array}{l}\text { HbA1c } \\
(\%)\end{array}$ \\
\hline All patients & 112 & $19.3 \pm 21.4$ & $9.3 \pm 7.3(83)$ & $\begin{array}{c}32.1 \pm 18 \\
(584 \pm 327)\end{array}$ & $142.3 \pm 43.3$ & $17.1 \pm 8.4$ & $\begin{array}{c}5.85 \pm 3.6 \\
(16.4 \pm 10.1)\end{array}$ & $11.3 \pm 3.6$ \\
\hline $\begin{array}{l}\text { T1DM } \\
\text { White }\end{array}$ & 66 & $16.5 \pm 11.78$ & $\begin{array}{c}9.3 \pm 6.2 \\
(47)\end{array}$ & $\begin{array}{c}30.6 \pm 15.8 \\
(558 \pm 288.8)\end{array}$ & $140.6 \pm 6.4$ & $17.2 \pm 7.3$ & $\begin{array}{c}5.96 \pm 2.7 \\
(16.7 \pm 7.8)\end{array}$ & $11.0 \pm 1.8$ \\
\hline $\begin{array}{l}\text { T1DM } \\
\text { African American }\end{array}$ & 25 & $19.5 \pm 13.2$ & $10.4 \pm 6.0(19)$ & $\begin{array}{l}37.8 \pm 23.7 \\
(688 \pm 432.3)\end{array}$ & $147.4 \pm 9$ & $14.7 \pm 7.2$ & $\begin{array}{c}7.17 \pm 4.9 \\
(20.1 \pm 13.8)\end{array}$ & $11.55 \pm 1.9$ \\
\hline T2DM & 21 & $25.5 \pm 22.1$ & $7.8 \pm 7.2(15)$ & $\begin{array}{l}29.1 \pm 15 \\
(530 \pm 271.6)\end{array}$ & $139.9 \pm 34$ & $20.9 \pm 7.2$ & $\begin{array}{c}3.99 \pm 2.1 \\
(11.2 \pm 5.9)\end{array}$ & $11.8 \pm 3.4$ \\
\hline Age $\leq 5$ years & 23 & $19.1 \pm 7.7$ & $\begin{array}{c}10.6 \pm 6.0 \\
(16)\end{array}$ & $\begin{array}{c}34.7 \pm 16.4 \\
(631 \pm 298.6)\end{array}$ & $145 \pm 9.2$ & $15.3 \pm 7.6$ & $\begin{array}{l}6.31 \pm 4 \\
(17.7 \pm 11.2)\end{array}$ & $10.75 \pm 2.1$ \\
\hline Age 6-12 years & 53 & $17.3 \pm 11.2$ & $9.2 \pm 5.9(38)$ & $\begin{array}{c}32.1 \pm 19.5 \\
(585 \pm 354.4)\end{array}$ & $141.5 \pm 22.1$ & $15.7 \pm 7.3$ & $\begin{array}{c}6.39 \pm 3.7 \\
(17.9 \pm 10.5)\end{array}$ & $11.4 \pm 2.3$ \\
\hline Age $\geq 13$ years & 36 & $22.7 \pm 20.1$ & $8.1 \pm 7.8(29)$ & $\begin{array}{c}30.3 \pm 17.4 \\
(552 \pm 315)\end{array}$ & $141.4 \pm 25.4$ & $20.3 \pm 7.8$ & $\begin{array}{c}4.81 \pm 2.4 \\
(13.5 \pm 6.9)\end{array}$ & $11.5 \pm 2.3$ \\
\hline Male & 53 & $18.6 \pm 14.3$ & $9.4 \pm 6.8(40)$ & $\begin{array}{c}30 \pm 19.5 \\
(547 \pm 354.7)\end{array}$ & $144.5 \pm 20.5$ & $15.9 \pm 7.8$ & $\begin{array}{c}5.92 \pm 2.9 \\
(16.6 \pm 8.2)\end{array}$ & $11.2 \pm 2.7$ \\
\hline Female & 59 & $20.4 \pm 14.8$ & $7.9 \pm 5.8(43)$ & $\begin{array}{c}27.9 \pm 16.4 \\
(509 \pm 296.9)\end{array}$ & $139.8 \pm 23.8$ & $18.3 \pm 6.6$ & $\begin{array}{c}5.96 \pm 3.8 \\
(16.7 \pm 10.9)\end{array}$ & $11.3 \pm 1.6$ \\
\hline With family history & 42 & $20.4 \pm 14.1$ & $\begin{array}{c}7.9 \pm 5.1 \\
(29)\end{array}$ & $\begin{array}{l}27.9 \pm 15.1 \\
(509 \pm 274.1)\end{array}$ & $139.8 \pm 26.4$ & $18 \pm 7.3$ & $\begin{array}{c}5.39 \pm 3.3 \\
(15.1 \pm 9.4)\end{array}$ & $11.1 \pm 2.4$ \\
\hline Without family history & 70 & $18.8 \pm 15.0$ & $\begin{array}{c}10.1 \pm 7.64 \\
(54)\end{array}$ & $\begin{array}{c}34.2 \pm 21.7 \\
(622 \pm 393.3)\end{array}$ & $143.2 \pm 24.9$ & $16.8 \pm 7.7$ & $\begin{array}{c}5.92 \pm 3.5 \\
(16.6 \pm 9.9)\end{array}$ & $11.45 \pm 2.1$ \\
\hline
\end{tabular}


presence or absence of diabetes in a first or second-degree relative. Mean $\mathrm{HbA} 1 \mathrm{c}$ was $11.3 \%$ for the entire group and showed similar values (10.75-11.8\%) in all subgroups. Mean blood glucose at diagnosis was $584 \mathrm{mg} / \mathrm{dl}$. A trend was apparent for African American children with T1DM to present with greater dehydration (higher corrected $\mathrm{Na}$ and BUN) and acidosis (lower $\mathrm{HCO}_{3}$ ) than either Caucasian children with T1DM or all children with T2DM. Caucasian children with T1DM had the shortest duration of polydypsia (14.2 days), followed by African American children with T1DM (19.5 days) and children with T2DM (25.5 days). Gender had no impact on presenting symptoms, duration of symptoms or laboratory parameters except that males had a somewhat lower $\mathrm{HCO}_{3}$ at diagnosis (15.9) than females (18.3). Family history of diabetes had little impact on duration of polydipsia, although weight loss and laboratory abnormalities were slightly more severe in patients without a family history of diabetes. When stratified by age, younger children ( $<5$ years of age) had greater weight loss (10.6\%), were more acidotic $\left(\mathrm{HCO}_{3}=15.3\right)$ and had slightly higher corrected serum $\mathrm{Na}(145 \mathrm{mmol} / \mathrm{L})$ than did older children $\left(8.1 \%\right.$ body weight loss, $\mathrm{HCO}_{3}=20.3 \mathrm{mmol} / \mathrm{L}$, and corrected $\mathrm{Na}=141.4 \mathrm{mmol} / \mathrm{L})(p<0.01)$, but mean $\mathrm{HbA} 1 \mathrm{c}$ in the younger children $(10.75 \%)$ was the lowest of any age group $(11.4 \%$ in $6-12$ year olds, and $11.5 \%$ in $\geq 13$ year olds). Of the total 66 Caucasians with T1DM, 25 children presented with DKA and of the total 25 black children with T1DM, 11 children presented with DKA.

To look for relationships between the different variables presented in Table 3, linear regression analysis was performed among all combinations of variables using Pearson correlation coefficients ( $r$ ). The relationship between the variables analyzed was complex, but certain significant correlations $(p<0.05)$ were noted.

1) Younger age $(p=0.007, r=0.26)$, greater weight loss $(p<0.001, r=0.54)$, and higher serum glucose $(p<0.001$, $r=-0.39$ ), but not duration of polydipsia (NS, $r=0.12$ ) correlated with a greater degree of acidosis (lower serum $\mathrm{HCO}_{3}$ ).

2) Higher glucose $(p<0.001, r=0.67)$, lower $\mathrm{HCO}_{3}$ $(p<0.001, r=-0.42)$, and higher corrected serum $\mathrm{Na}$ $(p<0.001, r=0.37)$ correlated with a higher BUN.

3) $\mathrm{HbA} 1 \mathrm{c}$ strongly correlated with $\%$ weight loss $(p=0.0015, r=0.35)$ and to a lesser degree with duration of polyuria $(p=0.03, r=0.21)$ and polydipsia $(p=0.017, r=0.24)$, but not with serum glucose (NS), corrected serum $\mathrm{Na}$ (NS), or BUN (NS).

4) Duration of polydipsia correlated with weight loss $(p=0.0064, r=0.31)$ and HbA1c $(p=0.017, r=0.24)$, and duration of polyuria correlated with weight loss $(p<0.04$, $r=0.3)$ and $\operatorname{HbA} 1 \mathrm{c}(p=0.03, r=0.21)$.

There was no correlation between the degree of ketonuria (mild, moderate, severe) and duration of polyuria and polydipsia.

\section{Discussion}

Only a few previous studies have examined laboratory data and presenting symptoms in new-onset childhood diabetes. These were over a decade ago and did not examine the impact of race on the presentation of T1DM. These reports also did not include T2DM as a separate group. It is possible that increased provider and public awareness of diabetes as well as the increased incidence of T2DM among children might have had an impact on the initial presentation of diabetes in children. Contrary to this hypothesis, we found that the prevalences of polyuria (91\%) and polydipsia (93\%) in our population were comparable to that found about a decade previously by Levy-Marchal (90\% had polyuria) (1) and Drash (90\% in males and $88 \%$ in females) (4). We also found a similar proportion of children with weight loss (68\%) as did Levy-Marchal (63\%) but this was less common than in the data from Drash (80\% in males and $84 \%$ in females). The mean percent weight loss in our study $(9.3 \%)$ was almost identical to that reported by Levy-Marshall (9.4\%). However, they reported a smaller percent weight loss $(7.9 \%)$ in the youngest children ( $\leq 4$ years of age) while we found the highest percent weight loss $(10.6 \%)$ in children $\leq 5$ years of age. This discrepancy could be due to the fact that we relied on parental reports of previous body weight (within 4 months of presentation).

Nearly half of parents in our study reported vomiting in the few days prior to presentation and this finding was often attributed to a viral illness. However $38 \%$ of children vomited only once, and in many cases this was more than a day prior to admission. Nevertheless, emesis was a late feature of diabetes in almost all cases.

The mean durations of polyuria and polydypsia prior to the diagnosis of diabetes were variable but typically in the 2-3 weeks range. Symptom duration is only an approximation, as many parents did not recall precisely when a particular symptom came to their attention. However our data are remarkably similar to that of a recent study of 109 children in Spain (7). They found that $95.8 \%$ of all children had polyuria and polydypsia. The mean duration of these symptoms was 25.4 days in children between 10-14 years of age; 21.7 days in children aged 5-9 years and 13.6 days in those $<4$ years old (7). In contrast, we found that the mean duration of polydypsia was 19.1 days in our youngest age group ( $\leq 5$ years). Mean duration for older children (17.3 days in 6-12 year olds and 22.7 days in children $\geq 13$ years of age) was similar to the Spanish data. In a large study of over 2000 children with T1DM, Neu et al (3) reported that the average duration of symptoms (11.2 days) was shorter among young children ( $<4$ years of age) than older (15.2 days). However, a greater proportion of young children (36\%) had DKA, while a smaller proportion (23\%) of older children presented with DKA. Their data suggest a more robust tempo of disease progression among young children. Similarly, Roche et al (8) reported that children $<2$ years of age are more likely to 
present with moderate to severe DKA. Our data offer a mixture of insights into these questions. In our study, the duration of polydypsia was the same for the young as for older children, but $\mathrm{HbA} 1 \mathrm{c}$ was actually lower in the young children. In contrast, mean $\mathrm{HCO}_{3}$ was lowest in our young patients ( $<5$ years of age), percentage of body weight loss was also greatest in this age group, and their mean serum glucose was highest compared to 6-12 year olds and older (>13 years) children. Similar to our data, Levy-Marchal et al found a higher proportion of children with $\mathrm{HCO}_{3}$ less than 18 $\mathrm{mmol} / \mathrm{L}$ in the $0-4$ year age group (66\%), as compared to the 10-19 year olds (30-48\%) (1). Whether or not these features really differ remains unclear. Despite this uncertainty, it is clear that the presenting symptoms and duration of symptoms have changed little if any over the previous decade despite an increase in the incidence of T2DM.

When we stratified our data by race and type of diabetes, we found that African American children with T1DM had a longer duration of polydipsia, that they were sicker and more dehydrated than Caucasian children. There are many possible explanations for this including limited access to health care among minority patients (6-9). Our data are consistent with the hypothesis that it takes longer for the parents of African American children to seek medical attention. On average, African American children had 5 more days of polydypsia than did Caucasian children. Interestingly, mean $\mathrm{HbA} 1 \mathrm{c}$ was only $0.5 \%$ higher in African American children with T1DM than in Caucasian children with T1DM. It is possible that some or all of this delay could arise from inadequate health insurance. We did not collect this data from our subjects but in a previous study, Mallare et al (9) found that $38 \%$ of 139 new onset T1DM children (0.5-18 years of age) presented with DKA. Those with Medicaid or no insurance were more likely to present with DKA (62\%) than were patients with private insurance (34\%). They concluded that lack of private insurance (a proxy for socioeconomic status) and young age were risk factors for DKA.

We also found that children with T2DM, all of whom were African American, had a longer duration of symptoms, little or no acidosis, and less dehydration when compared to all children with T1DM. This suggests that children with T2DM experienced a slower metabolic deterioration than children with T1DM. Despite this fact, $20 \%$ of children with T2DM in our study presented with DKA. This frequency is slightly higher than figures reported in previous studies (5-10\%) (5). We do not have an explanation for the increased prevalence of DKA, but it could be due to the longer duration of symptoms or more serious islet destruction.

One of the more intriguing findings of our study is that mean $\mathrm{HbA} 1 \mathrm{c}$ was close to $11 \%$ for the entire group and for every subgroup. Although Levy-Marchal et al (1) did not report HbA1c values; they reported mean glycosylated hemoglobin of $212 \%$ of the mean reference value which is similar to a $\mathrm{HbA} 1 \mathrm{c}$ value of $11 \%$. In a series of patients from Pittsburgh, mean $\mathrm{HbA} 1$ at diagnosis was $13.4 \%$ in males and
$14.9 \%$ in females. Using the formula $\mathrm{HbA} 1 \mathrm{c}=(\mathrm{HbA} 1-$ $0.19) / 1.2$, this approximates to an $\mathrm{HbA} 1 \mathrm{c}$ of $9.5 \%$ in males, and $10.8 \%$ in females. In our study, we did not find a malefemale difference in mean $\mathrm{HbA} 1 \mathrm{c}$ at the time of diagnosis. Barker et al (6) reported an average $\mathrm{HbA} 1 \mathrm{c}$ in symptomatic children with T1DM of $10.9 \%$. This was greater than that of children with pre-diabetes (HbA1c:7.2\%), patients who eventually progressed to overt diabetes. The similarity in all these studies and in our different subgroups suggests that regardless of age, gender, race and type of diabetes, all children have experienced a similar "glycemic exposure" at the time of diagnosis.

In contrast to our expectation, a family history of diabetes did not appear to result in earlier diagnosis. Patients with a positive family history of diabetes had a slightly longer duration of polydypsia than did patients without this history. A family history of diabetes may have mitigated against the severity of disease, since proportion of weight loss and laboratory abnormalities were less severe in the patients with a positive family history of diabetes.

By linear regression analysis we found that children who had a longer duration of polydypsia had a greater percentage of weight loss but not higher glucose, BUN, corrected $\mathrm{Na}$, or lower $\mathrm{HCO}_{3}$ levels. Thus a longer duration of symptoms did not necessarily equate with severity of illness. This suggests that the progression of disease may have been slower in children with a longer symptomatic period. The children who had more weight loss were significantly more acidotic and had higher HbA1c levels, but were not more dehydrated based on the corrected $\mathrm{Na}$ and BUN. Their weight loss may have been due to loss of body fat rather than acute dehydration.

Of major importance for primary care physicians, younger patients ( $\leq 5$ years old) were more acidotic and more dehydrated than older patients. A prolonged period of polyuria and polydipsia (>3 weeks) and more than $9 \%$ weight loss in children indicated a greater likelihood of DKA and a need for intensive care admission.

To our knowledge this is the first study in which parents of children with newly diagnosed diabetes were asked what prompted them to seek medical attention. Although about 90\% of the patients had polyuria and polydypsia, only $50 \%$ of parents sought medical care because of it. Therefore, primary care providers should have a high index of suspicion for diabetes in any child presenting with symptoms such as fatigue, poor appearance, and particularly weight loss. Ideally, blood glucose and/or urine testing should be done immediately. Unfortunately, several of the patients with the classic symptoms of $\mathrm{DM}$ are sent to a commercial lab for blood tests, and by the time the results are received a day or two later, the child will have progressed to DKA. This is especially common among young patients (9). The overall mortality rate from pediatric DKA in the United States is approximately $0.15 \%$, and cerebral edema accounts for $57-87 \%$ of deaths related to DKA (10). Earlier diagnosis and referral can prevent DKA and its complications. 
In summary, the most common presenting signs and symptoms of DM in children (polyuria, polydypsia and nocturia) have changed little over the past decade despite a dramatic increase in the incidence of T2DM. However, parents rarely bring their child to the physician for these symptoms. Rather they complain of fatigue, weight loss, a change in appearance, or vomiting (even if infrequent). Primary care physicians should be very astute to these complaints especially in the young child and those with suspected weight loss. The diagnosis of diabetes can be enhanced by rapid glucose testing in the office followed by referral and confirmation by laboratory studies at the time of hospitalization. Preventive health counseling should include discussions of the risk factors for T2DM (obesity, acanthosis nigricans, membership in high-risk minority populations, and family history of T2DM), and the signs and symptoms of diabetes in children.

\section{References}

1. Levy-Marchal C, Papoz L, de Beaufort C, Doutreix J, Froment V, Voirin J, Czernichow P. Clinical and laboratory features of type 1 diabetic children at the time of diagnosis. Diabet Med 1992; 9:279-284. [Abstract]

2. Scott CR, Smith JM, Cradock MM, Pihoker C. Characteristics of youth-onset noninsulin-dependent diabetes mellitus and insulin-dependent diabetes mellitus at diagnosis. Pediatrics 1997; 100:84-91. [Abstract] / [Full Text] / [PDF]

3. Neu A, Ehehalt S, Willasch A, Kehrer M, Hub R, Ranke MB. Varying clinical presentations at onset of type 1 diabetes mellitus in children-epidemiological evidence for different subtypes of the disease? Pediatr Diabetes 2001; 2:147-153. [Abstract] / [PDF]
4. Drash A. Diabetes in the child and adolescent. In: Wilkins The Diagnosis And Treatment Of Endocrine Disorders In Childhood And Adolescence, 4th ed. Springfield: Charles C. Thomas; 1994.

5. Kaufman FR. Type 2 diabetes in children and youth. Endocrinol Metab Clin North Am 2005; 34:659-676. [Abstract]

6. Barker JM, Goehrig SH, Barriga K, Hoffman M, Slover R, Eisenbarth GS, Norris JM, Klingensmith GJ, Rewers M. Clinical characteristics of children diagnosed with type 1 diabetes through intensive screening and follow-up. Diabetes Care 2004; 27:1399-1404. [Abstract] / [Full Text] / [PDF]

7. Cepedano DA, Barreiro CJ, Pombo AM. Incidence and clinical manifestation at onset of type 1 diabetes in Galacia (Spain). An Pediatr (Barc) 2005; 62:123-127. [Abstract] / [Full Text]

8. Roche EF, Menon A, Gill D, Hoey H. Clinical presentation of type 1 diabetes. Pediatr Diabetes 2005; 6:75-78. [Abstract] / [PDF]

9. Mallare JT, Cordice CC, Ryan BA, Carey DE, Kreitzer PM, Frank GR. Identifying risk factors for the development of diabetic ketoacidosis in new onset type 1 diabetes mellitus. Clin Pediatr (Phila) 2003; 42:591-597. [Abstract] / [PDF]

10. Dunger DB, Sperling MA, Acerini CL, Bohn DJ, Daneman D, Danne TP, Glaser NS, Hanas R, Hintz RL, Levitsky LL, Savage MO, Tasker RC, Wolsdori JI. ESPE/LWPES consensus statement on diabetic ketoacidosis in children and adolescents. Arch Dis Child 2004; 89:188-194. [Abstract] / [Full Text] / [PDF]

11. Hannon TS, Rao G, Arslanian SA. Childhood Obesity and Type 2 Diabetes Mellitus. Pediatrics 2005; 116; 473-480. [Abstract] / [Full Text] / [PDF] 